\title{
Quorum Quenching Mediated Bacteria Interruption as a Probable Strategy for Drinking Water Treatment against Bacterial Pollution
}

\author{
Jia Liu ${ }^{1,+}$, Xiaohui Sun ${ }^{1, *,+} \oplus$, Yuting Ma ${ }^{1}$, Junyi Zhang ${ }^{1} \mathbb{D}$, Changan $\mathrm{Xu}^{2}$ and \\ Shufeng Zhou $1, *$ (D) \\ 1 College of Chemical Engineering, Huaqiao University, Xiamen 361021, China; jialiu0505@outlook.com (J.L.); \\ uvtma@hotmail.com (Y.M.); junyi@hqu.edu.cn (J.Z.) \\ 2 Engineering Research Center of Marine Biological Resources Comprehensive Utilization, \\ Third Institute of Oceanography, Ministry of Natural Resources, Xiamen 361005, China; \\ xuchangan@tio.org.cn \\ * Correspondence: sunxiaohui@hqu.edu.cn (X.S.); szhou@hqu.edu.cn (S.Z.); Tel./Fax: +86-59-2616-2300 (X.S.); \\ +86-59-2616-2288 (S.Z.) \\ + These authors contributed equally to this work.
}

Received: 7 November 2020; Accepted: 6 December 2020; Published: 20 December 2020

check for updates

\begin{abstract}
Pseudomonas aeruginosa in water lines may cause bacteria pollution indrinking fountains that could affect the quality of potable water, thus posing a risk to public health. A clean and efficient strategy is required for drinking water treatment for food safety. In this study, an AiiA-homologous lactonase was cloned from a deep-sea probiotics Bacillus velezensis (DH82 strain), and was heterologously expressed so that the capacity of the enzyme on the N-acyl-L-homoserine lactone (AHL)-degrading, effect of bacterial proliferation, biofilm formation and toxic factors release, and membrane pollution from $P$. aeruginosa could each be investigated to analyze the effect of the enzyme on water treatment. The enzyme effectively degraded the signal molecules of $P$. aeruginosa (C6-HSL and C12-HSL), inhibited early proliferation and biofilm formation, significantly reduced toxic products (pyocyanin and rhamnolipid), and inhibited bacterial fouling on the filter membrane, which prevented the secondary contamination of $P$. aeruginosa in drinking water. The findings demonstrated that the quorum quenching enzyme from probiotics could prevent bacteria pollution and improve potable water quality, and that the enzyme treatment could be used as a probable strategy for drinking water treatment.
\end{abstract}

Keywords: quorum quenching; bacteria pollution; drinking water treatment; bacteria interruption; Pseudomonas aeruginosa

\section{Introduction}

As a result of the wide usage of drinking fountains and barreled drinking water, bacterial biofilms in drinking fountains and water lines may cause bacterial pollution that directly affects the quality of potable water (PW), and could pose a health risk to the public, usually through secondary bacterial infection [1]. Pseudomonas aeruginosa is a typical opportunistic pathogen that forms biofilms in water lines, one of the most critical factors monitored in PW systems [2]. At present, besides the thorough disinfection of instruments and supplied water, common methods of prevention and treatment against $P$. aeruginosa from biofilms are the usage of chemical drugs, such as antiseptics or antibiotics, which might affect food quality and cause problems of drug resistance [3] as a result of excessive release and irregular usage. Therefore, the disruption of bacterial biofilm formation might become 
a probable strategy to solve this problem [4], by using the bio-active, pollution-free, non-resistant, and non-toxic enzymes as substitutes.

Quorum sensing (QS) is a phenomenon that regulates bacterial population behavior by sensing the concentration of the auto-inducers, including spore formation, biofilms, and virulence expression [5]. QS isregulated by the threshold nature of signal initiation, the relative specificity of the signal-receptor, and the cascade nature of the regulatory process. P. aeruginosa has a typical hierarchical QS system, of which the LasI-LasR system [6] causes the auto-inducer, N-acyl-L-homoserine lactone (AHL), to regulate the downstream RhlI-RhlR [7] and PqsABCDE-PqsR [8] pathways by influencing the transcription and translation of the related genes [9]. Therefore, interference in the level of AHLs leads to quorum quenching (QQ) and has an effect the resulting QS reactions, such as biofilm forming [10] and the virulence expression [11] of P. aeruginosa. To date, research about $\mathrm{QQ}$ has been mainly focused on the enzymes that degrade the AHL signaling molecules, including three types of AHL, namely AHL-lactonase, -acylase, and -oxidoreductases [12], among which AHL-degrading enzymes are mostly characterized and isolated from the Bacillus genus [13]. Studies have also reported that QQ enzymes are sensitive to temperature and $\mathrm{pH}[14,15]$, meaning that they could easily be inactivated by water boiling, and cause no harmful effect in drinking water treatment.

In previous work, Bacillus velezensis (strain DH82) was isolated from the underlying sea water of a marine deep subsurface at a depth of $6000 \mathrm{~m}$ in the Western Pacific Yap trench, and was found to have a broad-spectrum antibacterial ability to affect biofilm-forming for most Gram-negative food-borne pathogens $[16,17]$, and to have the potential probiotic capacity to be applied to drinking water treatment. To address the QQ capacity of DH82 on antifouling against pathogens, and to identify the functional elements in DH82 on drinking water treatment, an AiiA homologous enzyme, named AiiA $A_{D H 82}$, with $93.7 \%$ consensus sequence to the reported $\mathrm{N}$-acyl homoserine lactone hydrolase (PDB: 3DHB), was cloned from the DH82 strain and expressed in thepET28a vector in E. coli. The investigation into the potential functional enzyme was focused on QQ activity against $P$. aeruginosa isolated from the water lines on the activity of AHL degrading, effect on biofilms forming and toxic factors releasing, and effect on the control of membrane pollution, in order to verify its capacity on QQ and its ability to halt $P$. aeruginosa contamination as a bioresource in drinking water treatment.

\section{Materials and Methods}

\subsection{Bacterial Strains and Reagents}

B. velezensis (DH82 strain; GenBank: MK203035) was isolated from the sea water samples of the Western Pacific Yap trench at the depth of $6000 \mathrm{~m}$, and was kindly offered by the Third Institute of Oceanography (Xiamen, China). P. aerugnosa wild-type strain was isolated from the water lines of drinking fountains in this study. The AHL reporter operon of LuxR-P $\mathrm{P}_{\text {luxI-laco }}$-RFP was provided by Xiamen University (Xiamen, China), and was conducted on pET28a in E. coli BL21 to detect the level of AHLs. N-Acyl-L-homoserine lactone hydrolase (PDB: 3DHB) from B. thuringiensis (GenBank: AY943832), named $\mathrm{Aii}_{3 \mathrm{DHB}}$, was used as the positive control to analyze the QQ activity of $\mathrm{Aii}_{\mathrm{DH} 82}$. All of the bacterial strains were cultured in a Luria-Bertani (LB) medium.

E. coli DH5 $\alpha$ and BL21 (DE3) competent cells were purchased from Transgen (Beijing, China). The restriction endonucleases and ligation enzymes were purchased from Takara Biotechnology (Dalian, China). The plasmid miniprep kit (Cat. GMK5999) and gel extraction kit (Cat. D2500-02) were purchased from Promega. N-( $\beta$-Ketocaproyl)-DL-homoserine lactone (C6-(L)-HSL, Cat. K3255) and (3-Oxododecanoyl)-L-homoserine lactone (3-oxo-C12-(L)-HSL, Cat. 09139) were purchased from Sigma-Aldrich (St. Louis, MO, USA).

\subsection{Genetic Engineering and Bioinformatic Analysis of $Q Q$ Enzyme}

The sequence of Aii $\mathrm{A}_{\mathrm{DH} 82}$ was amplified by PCR from the genomic DNA of DH82 using the primer aiiA-F (5'-atg acagtaaagaagctt tat ttc gtcc-3') and aiiA-R (5'-tta tat atattcagggaacactttacatcc 
$\left(c-3^{\prime}\right)$, and was digested by the restriction enzymes NdeI and XhoI, and subsequently ligated the multipile cloning sites into pET28a with the T4 ligase (Takara, China). The sequence obtained was analyzed by NCBI-BLAST and the maximum likelihood tree was computed using the Poisson correction method by MEGA7.0 software. The 3D structure of the enzyme was simulated using Swiss-model (https://swissmodel.expasy.org/). The bioinformatic information, including the smart domain (http://smart.embl-heidelberg.de/), was analyzed with TMHMM2.0 (https://services.healthtech. dtu.dk/service.php?Tmhmm-2.0).

\subsection{Protein Expression and Purification}

The expression clone of the QQ enzyme was driven by the T7 promoter, and the His-tag coding sequence on $\mathrm{pET} 28 \mathrm{a}$ encoded $6 x$ histidine to the $\mathrm{N}$-terminal of the target protein. The engineered plasmid was transferred in E. coli BL21 for protein expression. Then, $0.4 \mathrm{mM}$ of isopropyl- $\beta$-d-thiogalactoside (IPTG) was inoculated to the bacterial culture after $3 \mathrm{~h}$ in order to induce the expression of AiiA $\mathrm{DH}_{\mathrm{D} 82}$. The bacterial pellets were harvested after 20-hof incubation and resuspendeded using a lysis buffer (300 $\mathrm{mM} \mathrm{NaCl}$ and $50 \mathrm{mM} \mathrm{NaH}_{2} \mathrm{PO}_{4}(\mathrm{pH} 7.4)$ ), then washed with an imidazole elution buffer $(300 \mathrm{mM}$ $\mathrm{NaCl}, 200 \mathrm{mM}$ imidazole, and $50 \mathrm{mM} \mathrm{NaH}_{2} \mathrm{PO}_{4}(\mathrm{pH} 7.4)$ ). High affinity NI-NTA chromatography was used to purify the target protein. The purified protein was further analyzed with SDS-PAGE.

\subsection{In Vitro Assessment of AHL-Degrading Activity}

First, $100 \mu \mathrm{L}$ of $800 \mathrm{nmol} / \mathrm{L}$ AHL was mixed with $100 \mu \mathrm{L}$ of $1.5 \mathrm{mg} / \mathrm{mL}$ purified enzyme solution for pretreatment by letting it stand at $28^{\circ} \mathrm{C}$ for $45 \mathrm{~min}$. The E. coli carrying reporter operon was cultured overnight in LB media at $37^{\circ} \mathrm{C}$ with shaking at $200 \mathrm{rpm} / \mathrm{min}$, and injected with the pretreated AHL solution at 1:100 $(v / v)$, and was then incubated at $25^{\circ} \mathrm{C}$ and $180 \mathrm{rpm} / \mathrm{min}$ for $8 \mathrm{~h}$. The bacterial pellets carrying the reporter operon were centrifuged at $8000 \times g$ at $4{ }^{\circ} \mathrm{C}$, and resuspended with an equal volume of phosphate buffered saline (PBS; $8 \mathrm{mM} \mathrm{Na}_{2} \mathrm{HPO}_{4}, 137 \mathrm{mM} \mathrm{NaCl}, 2 \mathrm{mM} \mathrm{NaH}_{2} \mathrm{PO}_{4}(\mathrm{PH}=7.4)$ ). The fluorescence intensity of the bacterial pellets was measured with a fluorescence spectrophotometer at $620 \mathrm{~nm}$ (excitation wavelength at $584 \mathrm{~nm}$ ). The AHL-degrading activity of the QQ enzyme was determined by the relative fluorescence unit per cell, which was calculated by dividing the fluorescence intensity at $620 \mathrm{~nm}$ to the optical density of the bacterial culture at $595 \mathrm{~nm}$. Each experiment was repeated in triplicate.

\subsection{Growth Curve of P. aeruginosa}

The overnight culture of $P$. aeruginosa was diluted to $\mathrm{OD}_{600}$ value at 0.1 , and $10 \%$ was inoculated $(v / v)$ in $40 \mathrm{~mL}$ fresh LB broth with the addition of $4 \mathrm{~mL}$ of $1.5 \mathrm{mg} / \mathrm{mL}$ QQ enzyme; this was compared with $4 \mathrm{~mL}$ of sterile water, which was used as the negative control. The bacterial culture was sampled at $1,2,4,6,8,10$, and $12 \mathrm{~h}$ in order to obtain the growth curve.

\subsection{Microplate Biofilm Assay by Crystal Violet Staining}

P. aeruginosa cultures were grown statically in $200 \mu \mathrm{L}$ of biofilm medium (BM; filter sterilized tap water supplemented with $5 \mathrm{mM}$ sodium citrate, $0.5 \%$ casamino acids, and $0.5 \%$ brain heart infusion broth) at $30^{\circ} \mathrm{C}$ in a 96-well microplate for $3 \mathrm{~d}$, with the addition of $1.5 \mathrm{mg} / \mathrm{mL}$ QQ enzyme in triplicate. After washing with PBS, $200 \mu \mathrm{L}$ of $0.1 \%$ crystal violet solution was added to each well and left for $15 \mathrm{~min}$ at room temperature, after which the crystal violet was removed prior to three washes with PBS; $200 \mu \mathrm{L}$ of ethanol was then added to each well to dissolve any crystal violet bound to the well and any remaining biofilms. After $15 \mathrm{~min}$ at room temperature, the absorbance of the wells was measured at $600 \mathrm{~nm}$ using the Tecan Infinite M200 Pro. 


\subsection{Assessment of Virulence Factors from P. aeruginosa}

The $P$. aeruginosa overnight cultures were diluted to $\mathrm{OD}_{600}$ value at 0.1 , and mixed with $1.5 \mathrm{mg} / \mathrm{mL}$ QQ enzyme; this was compared with the control, which used the same amount of sterile water in triplicate. This was then incubated at $30{ }^{\circ} \mathrm{C}$ for $12 \mathrm{~h}$ and centrifuged at $8000 \times \mathrm{g} / \mathrm{min}$ for $5 \mathrm{~min}$ in order to collect the supernatant containing the released virulence factors (pyocyanin and rhamnolipid) generated by P. aeruginosa.

Then, $0.9 \mathrm{~mL}$ supernatant of bacterial culture was mixed through with $0.54 \mathrm{~mL}$ chloroform, and was allowed to stand for $5 \mathrm{~min}$ to collect the supernatant, which was then mixed with $0.2 \mathrm{~mL} \mathrm{HCl}$. Consequently, the absorbance of the upper liquid was measured at $520 \mathrm{~nm}$ so as to determine the content of pyocyanin.

Then, $1 \mathrm{~mL}$ supernatant of bacterial culture was mixed with $4 \mathrm{~mL}$ sulphuric acid-anthrone solution ( $0.2 \mathrm{~g}$ anthrone in $100 \mathrm{~mL}$ 85\% sulphuric acid), and was incubated in boiling water for $15 \mathrm{~min}$. The content of rhamnolipid was determined by the absorbance at $620 \mathrm{~nm}$.

\subsection{Effect of Antifouling on Watering Fountain}

A simulation system of biofilm contamination was assembled to quantify the biofouling of P. aeruginosa on the filter membrane, which consisted of a centrifuge tube and a vacuum suction filtration device connected to a catheter with a flow rate controller. The $0.22 \mu \mathrm{m}$ Polyvinylidene Fluoride (PVDF) filter membrane, pretreated with ultraviolet ray disinfection for $30 \mathrm{~min}$, was placed and fixed steadilybetween the filter cup and the sand-core funnel. P. aeruginosa cultures in BM were separately mixed with $1.5 \mathrm{mg} / \mathrm{mL}$ QQ enzyme and the negative control of sterile water, and were then continuously flowed into the filter cup at about 6 drops/min under the control of a flow controller, and then flowed through the PVDF filter membrane under using gravity. For $3 \mathrm{~d}$, the bacteria were intercepted so as to accumulate biofilms on the PVDF filter membrane.

The membrane flux $(\mathrm{g} / \mathrm{min})$ was used as an index of biofilm formation on the filter membrane, and was determined by the gravity of sterile water that flowed through the treated PVDF filter membrane per minute.

Each filter membrane was washed with PBS to remove the planktonic bacteria, and then stained in $2 \mathrm{~mL} 0.1 \%$ crystal violet in a clean petri dish for $15 \mathrm{~min}$ at room temperature. After further three washes with PBS to remove the uncombined crystal violet, $2 \mathrm{~mL}$ of $75 \%$ ethanol was added to the petri dish to dissolve the crystal violet on the remaining biofilm for $15 \mathrm{~min}$. The absorbance of the crystal violet solution at $600 \mathrm{~nm}$ was measured using Tecan Infinite M200 Pro so as to determine the biomass of the biofilm on the fouled filter membrane.

\subsection{Imaging of Filter Membrane}

Each PVDF filter membrane was washed with PBS three times, and then fixed with $2.5 \%$ glutaraldehyde solution at $4{ }^{\circ} \mathrm{C}$ for $2 \mathrm{~h}$. The fixed samples were successively dehydrated with $25 \%$, $50 \%, 75 \%, 95 \%(v / v)$ ethanol for $15 \mathrm{~min}$ each, and finally with 100\% ethanol for $30 \mathrm{~min}$. The dehydrated samples were immediately transferred to a vacuum oven for drying at $55^{\circ} \mathrm{C}$. The dried membranes under went sputter coating with a gold layer and were imaged with a field emission scanning electron microscope (SEM, SU5000, Hitachi, Japan) at $8 \mathrm{kV}$.

\subsection{Statistical Analysis}

Statistical significance of variance for the collected data was determined by $t$-tests in Origin 9.0 (Originlab, Northampton, MA, USA). A significant difference was indicated using *, a highly significant difference at $p<0.01$ was marked as ${ }^{* * *}$, a significant difference at $0.01<p<0.05$ was marked as ${ }^{* *}$, and $p>0.05$ was considered to be no difference. 


\section{Results}

\subsection{Construction of Expression Clone}

In this study, as shown in Figure 1, the sequence of aii $A_{\mathrm{DH} 82}$ was amplified from the genomic DNA of the DH82 strain, and cloned into the pET28a vector between the multiple cloning site of NdeI and XhoI. The expression clone was driven by T7 promoters and the His-tag coding sequence on the plasmid encoded $6 x$ histidine to the N-terminal of the target protein; the positive clone was amplified in E. coli $\mathrm{DH} 5 \alpha$ and transferred to E. coli BL21 for the protein expression. As shown in Figure 2, the result of the sequence alignment showed a93\% identity to that of the Bacillus cereus Y2 strain, and was homologous with that of B. thuringiensis (3DHB, AY943832.1) and B. Wiedmanni (C2PHZ1).

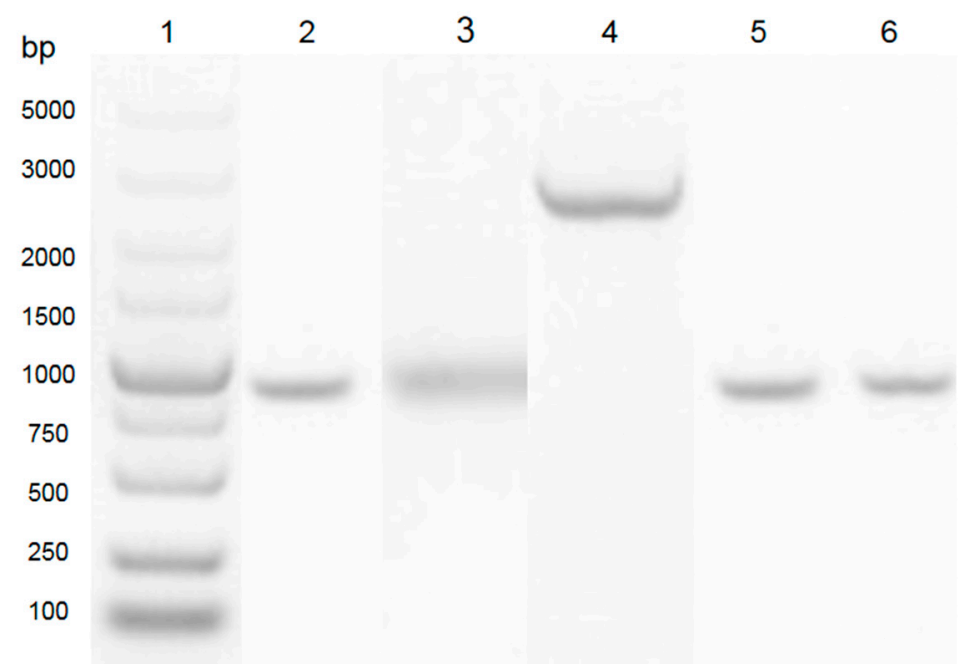

Figure 1. PCR amplification of the aii $A_{\mathrm{DH} 82}$ gene from B. velezensis (DH82 strain). Lane 1: DNA ladder (Takara, 3428Q). Lane 2: PCR product from B. velezensis (DH82 strain; aiiA homologue gene). Lane 3: DNA fragment of B. velezensis (DH82 strain; aiiA homologue gene) digested with enzymed NdeI and XhoI. Lane 4: cloing vector of pET28a digested with enzymes NdeI and XhoI. Lane 5: positive band confirmed from E. coli DH5 $\alpha$. Lane 6: positive band confirmed from E. coli BL21.

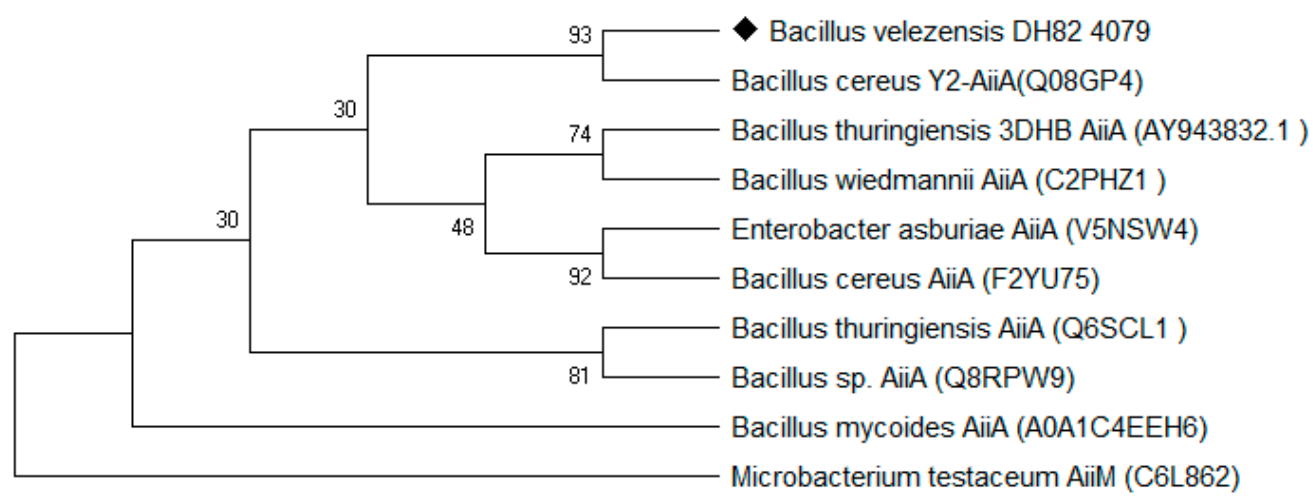

Figure 2. Neighbor-joining tree based on the AiiA from B. velezensis (DH82 strain).

The relationships between the other lactonase family are inferred using the maximum likelihood tree, computed using the Poisson correction method, compared with the reported N-acyl-L-homoserine lactone (AHL)-lactonase in the UniPro database. Evolutionary analyses have been conducted in MEGA7.0. 


\subsection{Bioinformatics Analysis and Expression of AiiA}

The bioinfomatics of Aii $A_{D H 82}$ were analyzed with the online tool ProtParam (http://www.expasy. org/tools/protparam). According to the results, the encoded Aii $A_{D H 82}$ was composed of 270 amino acids, with the isopotential point at $\mathrm{pH}$ 5.34. Among the amino acid residues, the contents of glutamic acid (Glu), glycine acid (Gly), and leucine acid (Leu) were relatively high, which exceeded $8 \%$ of the total components. The grand average of the hydropathicity (GRAVY) was -0.209 , which indicated Aii $A_{D H 82}$ as a hydrophilic protein. The predicted results also showed no transmembrane signal peptides on Aii $_{\mathrm{DH}}$ 2, which indicated that $\mathrm{Aii}_{\mathrm{DH} 82}$ belonged to a cytoplasmic enzyme. Like other known AHL-lactonase, Aii $\mathrm{A}_{\mathrm{DH} 82}$ contained two zinc binding domains (lactonase $\mathrm{B}$ and Metallo-beta-lactonase superfamily), and had lactamase activity. The 3D modeling of the enzyme structure was simulated and is shown in Figure 3A. Under the induction of $0.1 \mathrm{mM} \mathrm{IPTG}$, and incubation at $18^{\circ} \mathrm{C}$ for $20 \mathrm{~h}$, the target proteins of engineered $\mathrm{Aii}_{\mathrm{DH} 82}$ were harvested from bacterial extraction by $\mathrm{Ni}^{+}$affinity chromatography, as shown in Figure 3B, with a concentration of $1.5 \mathrm{mg} / \mathrm{mL}$.
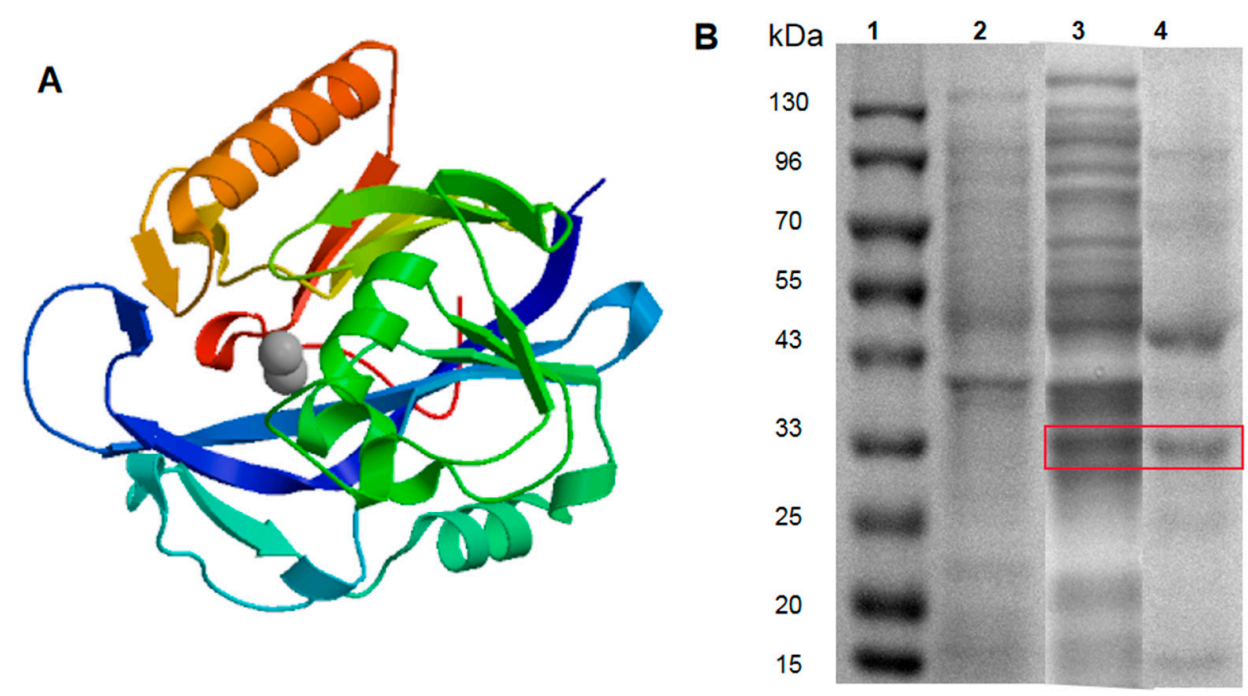

Figure 3. AiiA bioinformatics analysis and protein purification. Panel (A): Predicted 3D structure of

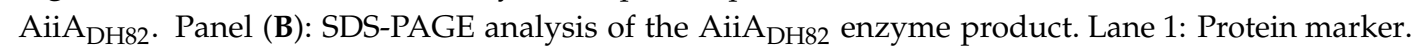
Lane 2: Extraction of non-load pET28a vector. Lane 3: Crude AiiA $A_{D H 82}$ enzyme extraction. Lane 4: Purified Aii $A_{\mathrm{DH} 82}$ enzyme extraction. The target protein bands in the gel are shown in the red frame.

\subsection{In Vitro Assessment of Ahls Degrading Capacity}

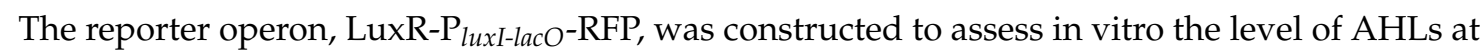
free status. As shown in Figure 4, two typical QS signals of P. aeruginosa, C6-HSL or C12-HSL, were used as substrates to assess the degrading capacity of the engineered $\mathrm{Aii}_{\mathrm{DH}} \mathrm{A}_{2}$, using the $\mathrm{Aii}_{3 \mathrm{DHB}}$ from $B$. thuringiensis as the positive control. The control groups that contained untreated AHL were used as the negative control and were labelled as CK1 and CK2. According to the results, the engineered Aii $_{\mathrm{DH} 82}$ presented a similar activity to the positive control on the degrading capacity against both C6-HSL $(p=0.00065)$ and C12-HSL $(p=0.021)$, and was observed to have significant difference to control checks (CKs), which indicated the QQ capacity of $\mathrm{Aii}_{\mathrm{DH} 82}$ on bacterial interruption against P. aeruginosa through the effect of the AHL level.

\subsection{Effect on Bacterial Interruption against P. Aeruginosa}

As shown in Figure 5A, the growth curves of P. aeruginosa show no significant difference with or without $A_{i i} A_{D H 82}$, however, the slope of the bacterial growth curve with the addition of $A_{i i} A_{D H 82}$ during the lag phase in the first $2 \mathrm{~h}$ was lower than in the absence of the QQ enzyme, which indicates that 
the QQ enzyme suppressed the increase of the bacterial biomass under a low cell density, and showed no effect on the bacteria once the cell density increased after the logarithmic phase.

As shown in Figure $5 \mathrm{~B}$, the presence of $\mathrm{Aii}_{\mathrm{DH} 82}$ significantly inhibited biofilms forming $P$. aeruginosa $(p=0.0013$ ), while the exogenous C6-HSL and C12-HSL showed no significant difference in the biomass increase of the bacterial biofilms, which indicated that Aii $A_{D H 82}$ interrupted the biofilms forming P. aeruginosa by degrading the AHLs in the bacterial culture, and verified that the exogenous AHLs would not affect the biomasses increasing once the endogenous AHLs were generated over the threshold value.

The virulence factors (pyocyanin and rhamnolipid) were both observed to be significantly down-regulated with the addition of $A_{i i} A_{D H 82}$, shown in Figures $5 C, D$, respectively, whose $p$-values were 0.0000095 and 0.015 , respectively. The results demonstrated that the QQ of AiiA ${ }_{\mathrm{DH} 82}$ mediated the level of AHLs, leading to an inhibition upon the release of pyocyanin and rhamnolipid, which educed the pathogenicity and potential risks of P. aeruginosa.

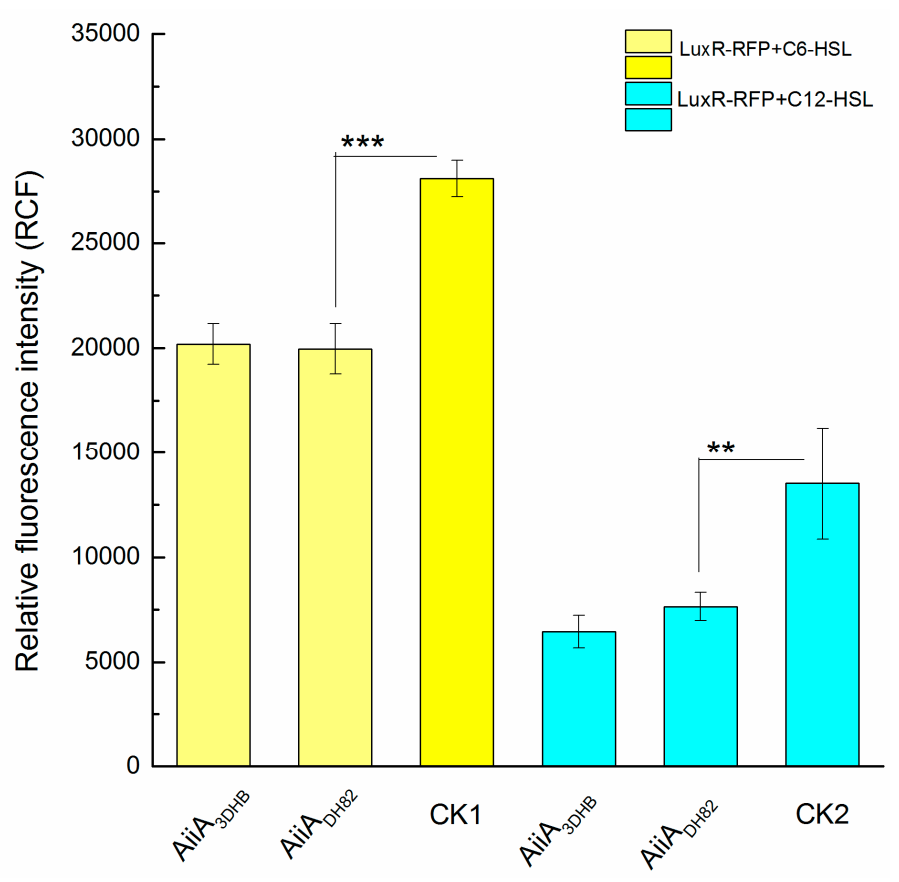

Figure 4. Activities of probable quorum quenching enzymes on AHL degradation. The degradation activities of $\mathrm{Aii}_{\mathrm{DH} 82}$ aredetermined by the relative fluorescence intensity generated bythe reporter

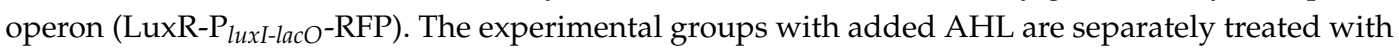
Aii $_{\text {DH82 }}$ (C6-HSL in yellow and C12-HSL in cyan), comparedwith the grouptreated with AiiA 3 DHB (used as the positive control) and the control checks (CKs) of untreated AHL. Error bars are used to determine the standard deviation. Statistical analysis results with a significant difference aremarked using * (significant differences at $p<0.01$ marked as ${ }^{* * *}$ and $0.01<p<0.05$ marked as ${ }^{* *}$ ).

\subsection{Trial Experiment of $Q Q$ Enzyme on Filter of Drinking Fountain}

The bacterial biofilm formation and permeability of the membrane were tested under the treatment of AiiA $A_{\mathrm{DH} 82}$ against P. aeruginosa. As shown in Figure 6, treatment of the QQ enzyme significantly inhibited the fouling of $P$. aeruginosa on the PVDF membrane, and the experimental group treated with a free $A_{i i} A_{D H 82}$ solution retained a high membrane permeability, while the membrane without the QQ enzyme had been blocked by the biofilm formed by P. aeruginosa after $3 \mathrm{~d}$, and the biofilm was visible to the naked eye in Panel A. The results of the crystal violet staining and membrane flux measurement are presented in Panel B, and the SEM images of the fouling layers are in Panel C also prove the antifouling capacity of $\mathrm{Aii}_{\mathrm{DH} 82}$. The results demonstrated that $\mathrm{QQ}$ enzyme treatment could be used as an effective strategy for antifouling as a water purifier in drinking fountains. 
A

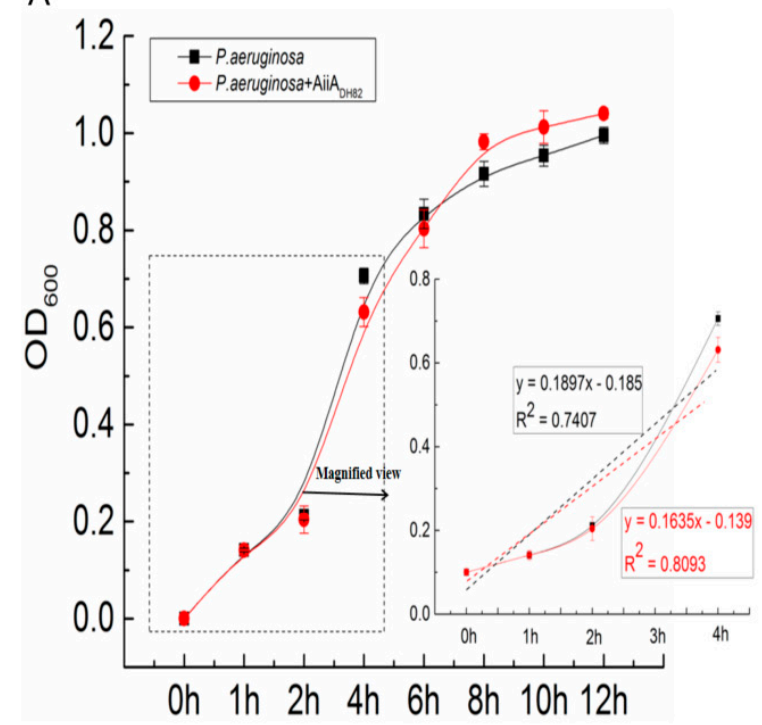

Oh $1 \mathrm{~h} 2 \mathrm{~h}$ 4h $6 \mathrm{~h}$ 8h $10 \mathrm{~h} 12 \mathrm{~h}$

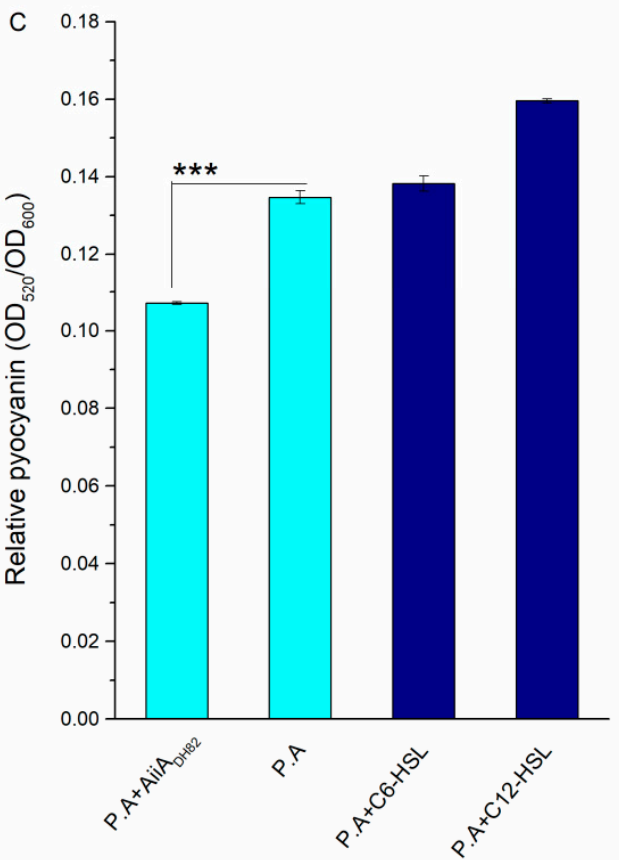

B
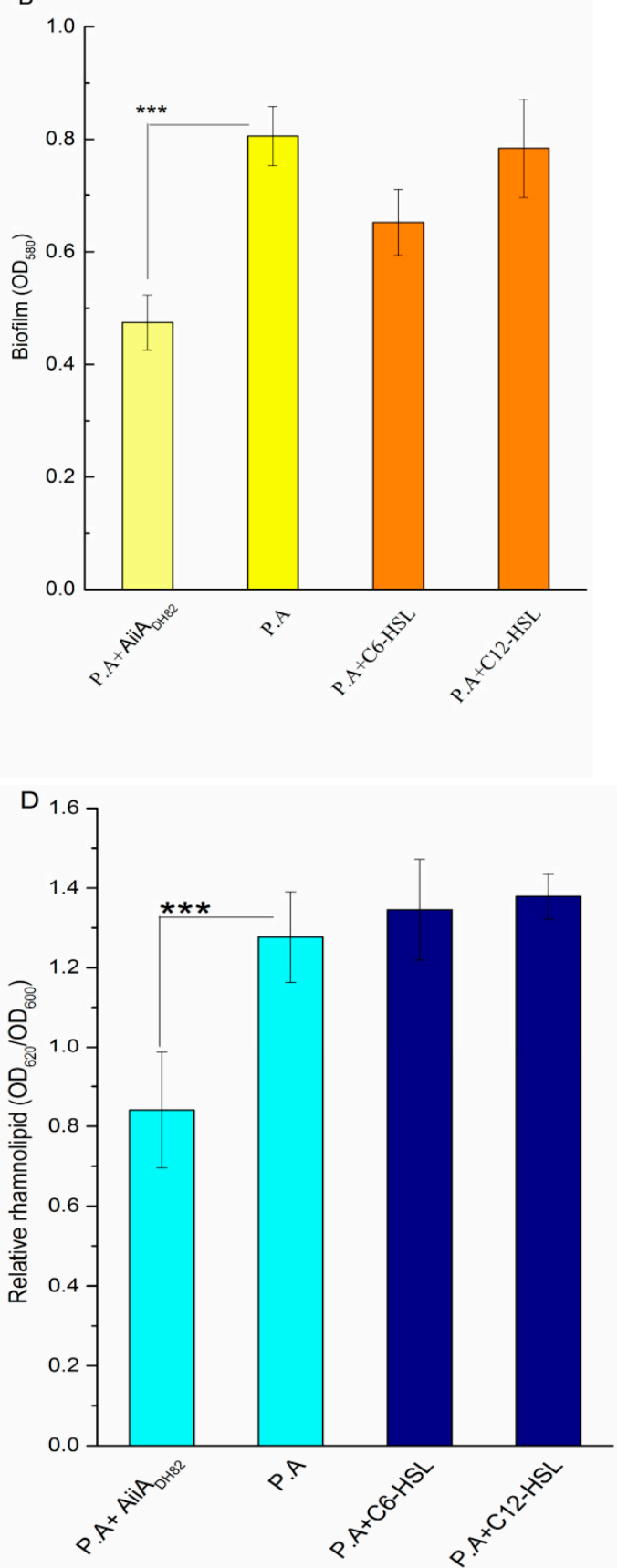

Figure 5. Bacterial interruption of thequorum quenching (QQ) enzyme against $P$. aeruginosa. Here, $1.5 \mathrm{mg} / \mathrm{mL}$ Aii $A_{\mathrm{DH} 82}$ was inoculated to the bacterial culture for treatment, the curve of bacterial density for growth, biofilm accumulation, and amount of released pyocyanin and rhamnolipid were determined by absorbance at $600,580,520$, and $620 \mathrm{~nm}$, respectively, measured using a microplate reader. Figure 5 shows the (A) growth curve of $P$. aeruginosa (bacterial culture with enzyme treatment in red, negative control in black), (B) biofilm formed by P. aeruginosa (biofilm with enzyme treatment in light yellow, non-treated biofilm in yellow, and biofilm with the addition of AHL in orange), (C) released pyocyanin, and (D) released rhamnolipid (bacterial culture with enzyme treatment in light cyan, non-treated bacterial culture in cyan, and bacterial culture with the addition of AHLs in navy). Error bars are present to determine the standard deviation. Statistic analysis results with significant difference are marked using * (significant differences at $p<0.01$ marked as ${ }^{* * *}$ ). 

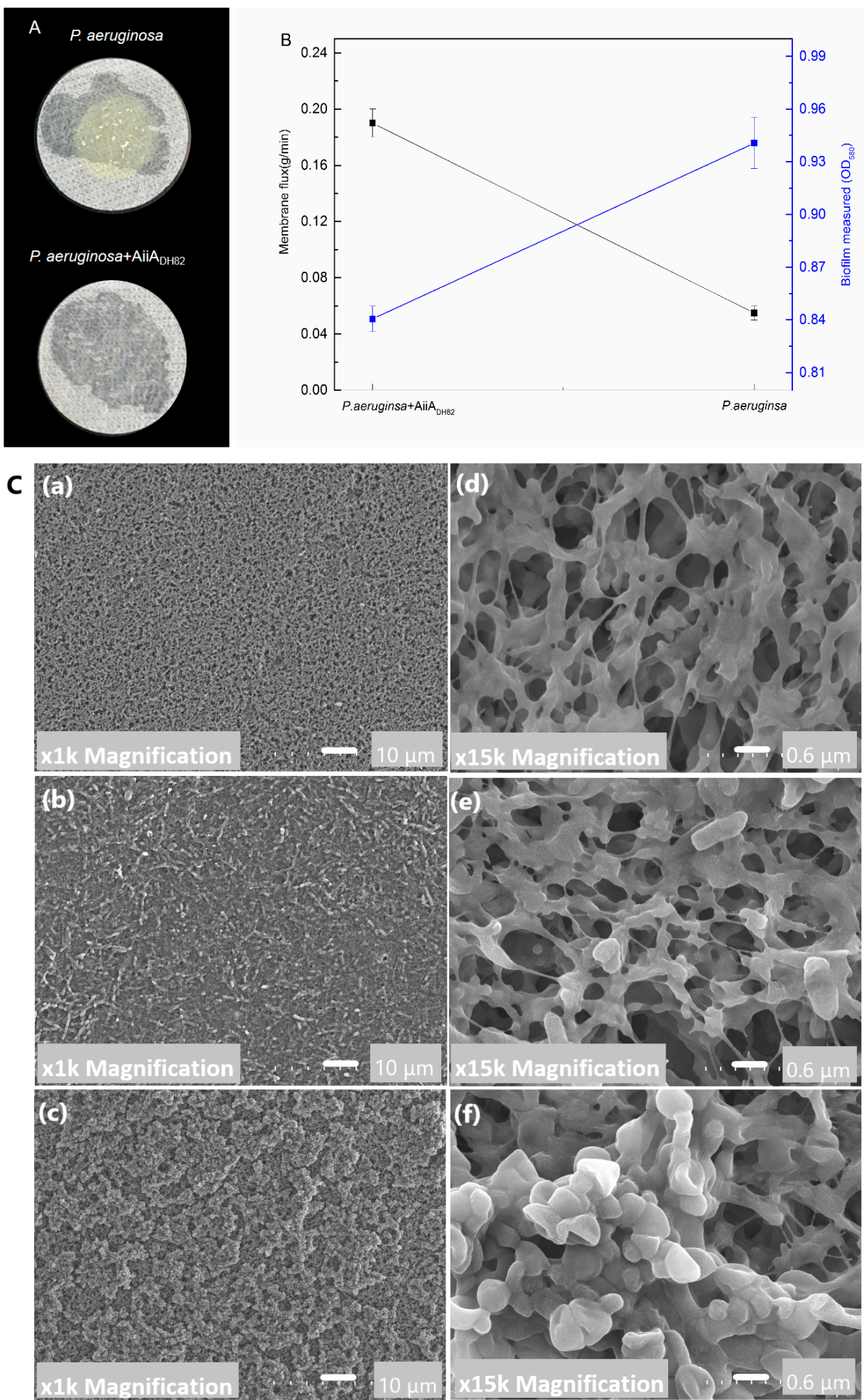

Figure 6. Antifouling capacity of the QQ enzyme against P. aeruginosa. Here, $1.5 \mathrm{mg} / \mathrm{mL}$ AiiA $\mathrm{D}_{\mathrm{DH}} 82$ ismixed with the bacterial culture and is continuously pumped through a $0.22 \mu \mathrm{m}$ PVDF filter membrane for 3 d. Panel (A): Pictures of the filter membrane. Panel (B): Biofilm and permeability after treatment. The permeability was determined by the flux of sterile water that flowed through the PVDF treated filter membrane per minute $(\mathrm{g} / \mathrm{min})$. The biomass of the biofilm stained by crystal violet is determined by absorbance at $600 \mathrm{~nm}$. The error bars present the standard deviation. Panel (C): SEM images of biomass accumulation on the PVDF membrane after $3 \mathrm{~d}$ of filtration. $(\mathbf{a}, \mathbf{d})$ New PVDF membrane at $100 \times$ and $15,000 \times$ magnification; (b,e) membrane treated with $\mathrm{Aii}_{\mathrm{DH} 82}$ at $1000 \times$ and $15,000 \times$ magnification; $(\mathbf{c}, \mathbf{f})$ untreated membrane at $1000 \times$ and $15,000 \times$ magnification. 


\section{Discussion}

The risk of $P$. Aeruginosa pollution does not just exist in the PW system, but also in a range of types of water, including hospital water, drinking water, and non-carbonated bottled water intended for human consumption, which also require the detection and enumeration of the most probable number (MPN) of P. aeruginosa (ISO 16266-2:2018), and would benefit from the performance of membrane filtration for water treatment. As an opportunistic pathogen, the physiological and metabolism activities of P. aeruginosa have not been extensively studied, which are mediated by QSs [18], including biofilm formation, antibiotic resistance, and virulence factor expression, which affect pathogenicity and host immunity $[10,19]$.

AHL-based QS and QQ have been studied for the application of biological wastewater treatment [20], mainly focusing on controlling the membrane biofouling in a membrane bioreactor (MBR) [21,22] using QQ bacteria [23] or enzymes [24]. The QQ enzyme has been found in different bacterial species, among which, AHL-lactonase has been found indifferent Bacillus spp. with a high identity of amino acid homology [13]; however, the application of QQ enzymes is still limited, as the sensitivity of temperature and $\mathrm{pH}[14,15]$ on the complex environment in MBR may inactivate the enzymes.

In this study, the engineered $\mathrm{Aii}_{\mathrm{DH} 82}$ was cloned from a potential probiotics strain isolated from deep-sea water, which showed no harm to the host according to previous studies. The effects of

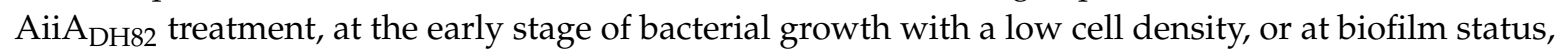
both demonstrated the positive inhibition of bacterial biomass accumulation and virulence factor release, by degrading AHLs to regulate the hierarchical QS system. The results of antifouling in the simulation system also demonstrated the direct interruption of $\mathrm{Aii}_{\mathrm{DH} 82}$ to P. aeruginosa in the bacterial culture, which indicated a feasible application in water treatment. As for the microfiltration process, using such a bio-active, pollution-free, non-resistant, and non-toxic enzyme as a substitute $[25,26]$, rather than bacteria strains $[23,27]$, was obviously a more reasonable strategy for drinking water treatment considering food safety and quality control.

On the other hand, AHLs and their analogs are small molecules that cross the bacterial membrane by osmosis, and bind to the receptors in bacteria and trigger the following quorum sensing by targeting protein phosphorylation [28,29]. N-hexanoyl-1-homoserine lactone (C6-HSL) and $\mathrm{N}$-(3-oxododecanoyl)-1-homoserine lactone (C12-HSL) perform a more consequential and eminent function in the biofilm maturation and virulence factor production in P. aeruginosa [30,31]. Although the addition of AHL did not significantly improve biofilm forming and virulence factor release, they did have an internal correlation, which might result from the fact that the accumulation of signal molecules reached the threshold and ignored the external addition. This phenomenon suggests that the universal microorganisms of the AHL-based QS system [5], such as Gram-negative bacteria, could be induced or inhibited interactively, and be affected by the addition of AiiA $\mathrm{DH}_{82}$.

Although QS is an ideal target to attenuate bacterial virulence and pathogenicity, the effects that QS inhibitors [32] or QQ enzymes [33] have on the broader microorganism communities or that signal alterations might exert on other outcomes in the environment are still of limited knowledge [34]. Therefore, it is highly desirable to further investigate the virulence roles of QS signals or QQ occuring under the influence of the overall environment, in order to diminish unpredicted impacts on food safety.

In order to solve the safety problem of domestic water supply, water purifiers for drinking fountains have become the last way to guarantee the safety of drinking water against pathogens. However, although the filter element of a water purifier could intercept most pollutants, it can easily form a bacterial biofilm on the filter membrane, which would cause membrane blockage and increase the risk of bacterial infection, thus affecting human health. Therefore, the application of the QQ enzyme could be an effective strategy for drinking water treatment, in order to solve the contamination problems caused by AHL-mediated pathogens such as P. aeruginosa. 


\section{Conclusions}

In this study, the AiiA homologous enzyme was cloned from a potential probiotic bacteria, B. velezensis(DH82 strain), isolated from the 6000-m deep subsurface of the Western Pacific Yap trench, and was heterologous expressed in order to investigate its QQ ability on AHL degrading, bacterial interruption in water contamination, and antifouling on the filter membrane. By intermediating the QS of the pathogen via degrading the AHL, the enzyme of Aii $A_{D H 82}$ was observed to provide significant inhibition on early proliferation, biofilm formation, and virulent factor release of $P$. aeruginosa (including pyocyanin and rhamnolipid), therefore inhibiting the bacterial fouling of P. aeruginosa on the filters of drinking fountains. The findings indicate that the QQ enzyme of Aii $A_{\mathrm{DH} 82}$ could be used as an effective approach to prevent and control the microbial contamination of drinking water, and to reduce the risk of infection by the opportunistic pathogen P. aeruginosa.

Author Contributions: X.S. contributed to the conception of the study and drafted the manuscript; J.L. performed the experiments and analyzed the data; Y.M. helped perform the antifouling experiment; X.S. and J.L. contributed significantly to the analysis of the results; X.S. and J.Z. helped analyze with constructive discussions; X.S., C.X., and S.Z. offered the funding acquisition. All authors have read and agreed to the published version of the manuscript.

Funding: The project was sponsored by start-up research funding from Huaqiao University (605-50Y19014) and the cooperative research project between Huaqiao University and Fujian Huisheng Biotech Ltd. (605-54319210). The authors would also like to thank the funding support from the subsidized Project for Postgraduates' Innovative Fund in Scientific Research of Huaqiao University, as well as the Undergraduate Innovation and Entrepreneurship Training Program of Fujian Province.

Acknowledgments: Thanks to Changan Xu for providing the B. velezensis (DH82 strain), and to Baishan Fang for providing the AHL reporter operon of LuxR-P $\mathrm{P}_{\text {luxI-lac }}$-RFP.

Conflicts of Interest: The authors declare no conflict of interest.

\section{References}

1. Liao, Z.; Cao, D.L.; Zhang, H.; Zhao, X. Current situation and existing problems of packaged drinking water industry in China. J. Food Saf. Qual. 2017, 8, 737-741.

2. English, E.L.; Schutz, K.C.; Willsey, G.G.; Wargoa, M.J. Transcriptional responses of Pseudomonas aeruginosa to potable water and freshwater. Appl. Environ. Microbiol. 2018, 84, 02350-17. [CrossRef] [PubMed]

3. Pang, Z.; Raudonis, R.; Glick, B.R.; Lin, T.J.; Cheng, Z. Antibiotic resistance in Pseudomonas aeruginosa: Mechanisms and alternative therapeutic strategies. Biotechnol. Adv. 2019, 37, 177-192. [CrossRef] [PubMed]

4. Huang, J.H.; Gu, Y.L.; Zeng, G.M.; Yang, Y.; Shi, L.X.; Shi, Y.H.; Yi, K.X. Control of indigenous quorum quenching bacteria on membrane biofouling in a short-period MBR. Bioresour. Technol. 2019, 283, 261-269. [CrossRef]

5. Ng, W.L.; Bassler, B.L. Bacterial quorum-sensing network architectures. Annu. Rev. Genet. 2009, 43, $197-222$. [CrossRef]

6. Sappington, K.J.; Dandekar, A.A.; Oinuma, K.; Greenberg, E.P. Reversible Signal Binding by the Pseudomonas aeruginosa Quorum-Sensing Signal Receptor LasR. MBio 2011, 2, 1-6. [CrossRef]

7. Oinuma, K.; Greenberg, E.P. Acyl-homoserine lactone binding to and stability of the orphan Pseudomonas aeruginosa quorum-sensing signal receptor, QscR. J. Bacteriol. 2011, 193, 421-428. [CrossRef]

8. Li, W.R.; Zeng, T.H.; Xie, X.B.; Shi, Q.S.; Li, C.L. Inhibition of the pqsABCDE and pqsH in the pqs quorum sensing system and related virulence factors of the Pseudomonas aeruginosa PAO1 strain by farnesol. Int. Biodeterior. Biodegrad. 2020, 151, 104956. [CrossRef]

9. Lee, J.; Zhang, L. The hierarchy quorum sensing network in Pseudomonas aeruginosa. Protein Cell. 2014, 6, 26-41. [CrossRef]

10. Mukherjee, S.; Moustafa, D.; Smith, C.D.; Goldberg, J.B.; Bassler, L. The RhlR quorum-sensing receptor controls Pseudomonas aeruginosa pathogenesis and biofilm development independently of its canonical homoserine lactone autoinducer. PLoS Pathog. 2017, 13, e1006504. [CrossRef]

11. Rampioni, G.D.; Bondì, R.; Imperi, F.; Fimia, G.M.; Visca, P.; Zennaro, E.; Leoni, L. A New Transcriptional Repressor of the Pseudomonas aeruginosa Quorum Sensing Receptor Gene lasR. PLoS ONE 2013, 8, e69554.

12. Fetzner, S. Quorum quenching enzymes. J. Biotechnol. 2015, 201, 2-14. [CrossRef] [PubMed] 
13. Dong, Y.; Xu, J.; Li, X.; Zhang, L. AiiA, an enzyme that inactivates the acylhomoserine lactone quorum-sensing signal and attenuates the virulence of Erwinia carotovora. Proc. Natl. Acad. Sci. USA 2000, 97, 3526-3531. [CrossRef]

14. Achari, G.A.; Ramesh, R. Characterization of quorum quenching enzymes from endophytic and rhizosphere colonizing bacteria. Biocatal. Agric. Biotechnol. 2018, 13, 20-24. [CrossRef]

15. Rana, S.; Bhawal, S.; Kumari, A.; Kapila, S.; Kapila, R. pH-dependent inhibition of AHL-mediated quorum sensing by cell-free supernatant of lactic acid bacteria in Pseudomonas aeruginosa PAO1. Microb. Pthogenes. 2020, 142, 104-105. [CrossRef] [PubMed]

16. Wang, Q.H.; Sun, X.H.; Tang, X.; Wan, J.L.; Xu, C.A. Screening and identification of Bacillus velezensis strain DH82 and the characterization of the crude antimicrobial protein. Mar. Sci. Bull. 2019, 38, 63-69.

17. Wang, Q.H.; Sun, X.H.; Tang, X.; Wan, J.L.; Xu, C.A. Purification of antimicrobial substance produced by deep sea Bacillus velezensisstrain DH82 and its inhibition spectrum. J. Appl. Oceanogr. 2020, 39, 20-26.

18. Telford, G.; Wheeler, D.; Williams, P.; Tomkins, P.T.; Appleby, P.; Sewell, H.; Stewart, G.S.; Bycroft, B.W.; Pritchard, D.I. The Pseudomonas aeruginosa quorum-sensing signal molecule N-(3-Oxododecanoyl)-L-homoserine lactone has immunomodulatory activity. Infect. Immun. 1998, 66, 36-42. [CrossRef]

19. Chan, K.G.; Liu, Y.C.; Chang, C.Y. Inhibiting N-acyl-homoserine lactone synthesis and quenching Pseudomonas quinolone quorum sensing to attenuate virulence. Front. Microbiol. 2015, 6, 1-7. [CrossRef]

20. Huang, J.; Shi, Y.H.; Zeng, G.M.; Gu, Y.L.; Chen, G.Q.; Shi, L.X.; Hu, Y.; Tang, B.; Zhou, J.X. Acyl-homoserine lactone-based quorum sensing and quorum quenching hold promise to determine the performance of biological wastewater treatments: An overview. Chemosphere 2016, 157, 137-151. [CrossRef]

21. Lee, J.; Won, Y.; Choi, D.; Lee, S.; Park, P. Micro-patterned membranes with enzymatic quorum quenching activity to control biofouling in an MBR for wastewater treatment. J. Memb. Sci. 2019, 592, 117365. [CrossRef]

22. Khan, M.; Khan, S.J.; Hasan, S.W. Biomass and Bioenergy Quorum sensing control and wastewater treatment in quorum quenching/submerged membrane electro-bioreactor (SMEBR (QQ)) hybrid system. Biomass Bioenergy 2019, 128, 105329. [CrossRef]

23. Liu, J. Quorum quenching in anaerobic membrane bioreactor for fouling control. Water Res. 2019, 156, 159-167. [CrossRef] [PubMed]

24. Hee, T.; Lee, I.; Yeon, K.; Kim, J. Biocatalytic membrane with acylase stabilized on intact carbon nanotubes for effective antifouling via quorum quenching. J. Memb. Sci. 2018, 554, 357-365.

25. Wang, M.; Mohanty, S.K.; Mahendra, S. Nanomaterial-Supported Enzymes for Water Purification and Monitoring in Point-of-Use Water Supply Systems. Acc. Chem. Res. 2019, 52, 876-885. [CrossRef]

26. Arregui, L.; Ayala, M.; Gómez-Gil, X.; Gutiérrez-Soto, G.; Hernández-Luna, C.E.; Santos, M.H.D.L.; Levin, L.; Rojo-Domínguez, A.; Romero-Martínez, D.; Saparrat, M.C.N.; et al. Laccases: Structure, function, and potential application in water bioremediation. Microb. Cell Factories 2019, 18, 1-33. [CrossRef]

27. Ham, S.Y.; Kim, H.S.; Cha, E.; Park, J.H.; Park, H.D. Mitigation of membrane biofouling by a quorum quenching bacterium for membrane bioreactors. Bioresour.Technol. 2018, 258, 220-226. [CrossRef]

28. Castillon, G.A. Induction and inhibition of Pseudomonas aeruginosa quorum sensing by synthetic autoinducer analogs. Chem. Biol. 2003, 13, 654-658.

29. Jiang, Y. In vitro biosynthesis of the Pseudomonas aeruginosa quorum-sensing signal molecule N-butanoyl-L-homoserine lactone. Mol. Microbiol. 1998, 28, 193-203. [CrossRef]

30. Alayande, A.B.; Aung, M.M.; Kim, I.S. Correlation Between Quorum Sensing Signal Molecules and Pseudomonas aeruginosa's Biofilm Development and Virulency. Curr. Microbiol. 2018, 75, 787-793. [CrossRef]

31. Smith, R.S.; Harris, S.G.; Phipps, R.; Iglewski, B. The Pseudomonas aeruginosa Quorum-Sensing Molecule $\mathrm{N}$-(3-Oxododecanoyl) Homoserine Lactone Contributes to Virulence and Induces Inflammation In Vivo. J. Bacteriol. 2002, 184, 1132-1139. [CrossRef] [PubMed]

32. Annapoorani, A.; Umamageswaran, V.; Ravi, A.V. Computational discovery of putative quorum sensing inhibitors against LasR and RhlR receptor proteins of Pseudomonas aeruginosa. J. Comput. Aided. Mol. Des. 2012, 26, 1067-1077. [CrossRef] [PubMed]

33. Bzdrenga, J. Biotechnological applications of quorum quenching enzymes. Chem. Biol. Interact. 2017, 267, 104-115. [CrossRef] [PubMed] 
34. Decho, A.W.; Norman, R.S.; Visscher, P.T. Quorum sensing in natural environments: Emerging views from microbial mats. Trends Microbiol. 2010, 18, 73-80. [CrossRef] [PubMed]

Publisher's Note: MDPI stays neutral with regard to jurisdictional claims in published maps and institutional affiliations.

(C) 2020 by the authors. Licensee MDPI, Basel, Switzerland. This article is an open access article distributed under the terms and conditions of the Creative Commons Attribution (CC BY) license (http://creativecommons.org/licenses/by/4.0/). 